\title{
An Introduction to Queueing Theory and Matrix-Analytic Methods
}

by

\section{BREUER}

University of Trier, Germany

and

D. BAUM

University of Trier, Germany 


\section{Contents}

List of Figures $\quad$ ix

Foreword xi

1. QUEUES: THE ART OF MODELLING 1

Part I Markovian Methods

2. MARKOV CHAINS AND QUEUES IN DISCRETE TIME 11

1 Definition 11

2 Classification of States 15

3 Stationary Distributions 20

4 Restricted Markov Chains 27

5 Conditions for Positive Recurrence 29

6 The $\mathrm{M} / \mathrm{M} / 1$ queue in discrete time 31

3. HOMOGENEOUS MARKOV PROCESSES ON DISCRETE STATE SPACES 39

1 Definition 39

2 Stationary Distribution 46

4. MARKOVIAN QUEUES IN CONTINUOUS TIME 51

1 The $\mathrm{M} / \mathrm{M} / 1$ Queue 51

2 Skip-Free Markov Processes 54

3 The $\mathrm{M} / \mathrm{M} / \infty$ Queue 55

4 The M/M/k Queue 56

5 The $M / M / k / k$ Queue 58

6 The $\mathrm{M} / \mathrm{M} / \mathrm{k} / \mathrm{k}+\mathrm{c} / \mathrm{N}$ Queue $\quad 59$ 
5. MARKOVIAN QUEUEING NETWORKS 63

1 Balance Equations and Reversibility Properties 65

2 Jackson and Gordon-Newell Networks 80

3 Symmetric Service Disciplines 99

Part II Semi-Markovian Methods

6. RENEWAL THEORY 113

1 Renewal Processes 113

2 Renewal Function and Renewal Equations 116

3 Renewal Theorems 118

4 Residual Life Times and Stationary Renewal Processes 124

5 Renewal Reward Processes 130

7. MARKOV RENEWAL THEORY 135

1 Regenerative Processes 135

2 Semi-Markov Processes 138

3 Semi-regenerative Processes 144

8. SEMI-MARKOVIAN QUEUES 147

1 The GI/M/1 Queue 147

2 The $M / G / 1$ Queue $\quad 155$

3 The GI/M/m Queue 160

Part III Matrix-Analytic Methods

9. PHASE-TYPE DISTRIBUTIONS 169

1 Motivation 169

2 Definition and Examples 171

3 Moments 176

4 Closure Properties 178

10. MARKOVIAN ARRIVAL PROCESSES 185

1 The PH renewal process 185

2 From PH renewal processes to MAPs 187

3 From MAPs to BMAPs 188

4 Distribution of the Number of Arrivals 190

5 Expected Number of Arrivals 192 
11. THE GI/PH/1 QUEUE

1 The Embedded Markov Chain 198

2 Stationary Distribution at Arrival Instants 199

3 Ergodicity of the Embedded Markov Chain 204

4 Asymptotic Distribution of the System Process 208

12. THE BMAP/G/1 QUEUE 213

1 The Embedded Markov Chain 214

2 The Matrix G 215

3 Stationary Distribution at Service Completions 216

4 Asymptotic Distribution of the System Process 218

5 Stability Conditions 224

13. DISCRETE TIME APPROACHES 229

1 Discrete Phase-Type Distributions 229

2 BMAPs in Discrete Time 232

3 Blockwise Skip-Free Markov Chains 234

4 The PH/PH/1 Queue in Discrete Time 236

14. SPATIAL MARKOVIAN ARRIVAL PROCESSES 239

1 Arrivals in Space 240

2 Properties of Spatial MAPs 245

15. APPENDIX 253

1 Conditional Expectations and Probabilities 253

2 Extension Theorems 256

3 Transforms 258

4 Gershgorin's Circle Theorem 260

References 263

Index 